\title{
Effect of Ultrasonic Nanocrystal Surface Modification on the Microstructure and Martensitic Transformation of Selective Laser Melted Nitinol
}

\author{
C.A. Biffi ${ }^{1, *}$, P. Bassani ${ }^{1}{ }^{1}$, M. Nematollahi ${ }^{2} \oplus$, N. Shayesteh Moghaddam ${ }^{3}$, A. Amerinatanzi $^{3}$, \\ M.J. Mahtabi ${ }^{4}$, M. Elahinia ${ }^{2}$ (D) and A. Tuissi ${ }^{1}$ \\ 1 National Research Council; Institute of Condensed Matter Chemistry and Technologies for Energy, \\ CNR ICMATE, Unit of Lecco, Via Previati 1E, 23900 Lecco, Italy; paola.bassani@cnr.it (P.B.); \\ ausonio.tuissi@cnr.it (A.T.) \\ 2 Dynamic and Smart Systems Laboratory, Mechanical Industrial and Manufacturing Engineering \\ Department, The University of Toledo, Toledo, OH 43606, USA; m.nematolahi@gmail.com (M.N.); \\ mohammad.elahinia@utoledo.edu (M.E.) \\ 3 Mechanical and Aerospace Engineering, University of Texas at Arlington, Arlington, TX 76019, USA; \\ narges.shayestehmoghaddam@rockets.utoledo.edu (N.S.M.); \\ amirhesam.amerinatanzi@rockets.utoledo.edu (A.A.) \\ 4 Department of Mechanical Engineering, University of Tennessee at Chattanooga, \\ Chattanooga, TN 37403, USA; mohammad.javad.mahtabioghani@utoledo.edu \\ * Correspondence: carloalberto.biffi@cnr.it
}

Received: 24 July 2019; Accepted: 10 September 2019; Published: 20 September 2019

check for updates

\begin{abstract}
Nitinol has significant potential for biomedical and actuating-sensing devices, thanks to its functional properties. The use of selective laser melting (SLM) with Nitinol powder can promote novel applications aimed to produce 3D complex parts with integrated functional performances. As the final step of the production route, finishing processing needs to be investigated both for the optimization of the surface morphology and the limit alteration of the Nitinol functional properties. In this work, the effect of an advanced method of surface modification, ultrasonic nanocrystal surface modification (UNSM), on the martensitic transformation and microstructure of SLM built Ni50.8Ti49.2 (at.\%) was investigated. Scanning electron microscopy, $\mathrm{X}$-ray diffraction, and differential scanning calorimetry indicated that the UNSM process can generate stress-induced martensite, at least partially suppressing the martensitic transformation. The microhardness profile indicates that the UNSM process can affect the mechanical properties of the SLMed Nitinol sample in a range of up to approximately $750 \mu \mathrm{m}$ in depth from the upper surface, while electron backscatter diffraction analysis highlighted that the initial austenitic phase was modified within a depth below $200 \mu \mathrm{m}$ from the UNSMed surface.
\end{abstract}

Keywords: NiTi; selective laser melting; ultrasonic nano-crystal surface modification; EBSD; microstructure; XRD

\section{Introduction}

Quasi-equiatomic NiTi alloys are the most diffused shape memory alloys (SMAs), thanks to their stable and optimal functional properties, namely shape memory effect and pseudoelasticity [1]. These properties depend on martensitic transformation (MT) and can be found in Ti-rich NiTi and Ni-rich NiTi alloys above or below room temperature, respectively. As the operating temperatures of the MT are affected strongly by the Ni/Ti ratio, the manufacturing of the NiTi SMAs is very challenging for getting stable functional characteristics [2].

In recent years, the use of additive manufacturing (AM) techniques for realizing 3D parts in NiTi alloys has become an attractive solution for advanced devices [3-7]. The feasibility of manufacturing 
Nitinol through different AM technologies, like selective laser melting (SLM), electron beam melting, and direct energy deposition, has been demonstrated in several experimental works [8-10]. Of the AM methods, the SLM process is the most investigated one, since it can offer the best compromise between product quality, productivity, and diffusion in the market. The MT and the related functional properties of SLM-built Nitinol parts have been shown to be almost comparable to those of the wrought alloy under compression testing [11-13], while the tensile behavior is less consolidated, due to the problem of residual porosity $[14,15]$. The compositional issue remains an aspect to be well controlled during the laser process in order to allow an appropriate $\mathrm{Ni} / \mathrm{Ti}$ ratio for inducing the MT $[16,17]$. Moreover, the microstructure obtained by SLM is strongly textured and this can be optimized for enhancing the functional response of the NiTi alloy [18].

However, this is not enough for fixing the final performance of the device. In detail, SLM often requires the adoption of post-processing treatments, not only for inducing tailored microstructures through heat treatments but also surface modifications [19,20], due to high roughness values and relevant dimensional errors [21,22]. The literature reports some works regarding the performances of conventional treatments, like electropolishing [23,24], and advanced finishing post-processing, like laser shock peening [25,26] and ultrasonic nanocrystal surface modification (UNSM) [27-29], on NiTinol samples. The main achievements obtained during the surface modification processing were good surface roughness values and improved surface responses, such as wear resistance, fatigue behavior, and biological response.

So far, only a few of these works have focused on SLMed NiTi parts [24,29]. As the initial surface condition and the mechanical properties of a rolled NiTi tape or wire are pretty different from the ones of an SLMed component, the performances of the post-processing treatments should be revised for the AMed NiTi alloys. In fact, in a previous work the effect of the main SLM process parameters on the performances of electropolishing on NiTi samples containing interior channels was studied [24]. It was found that electropolishing can decrease the roughness only for low power densities, thanks to the smaller melt pools and columnar structures. In another work, the effect of the UNSM treatment on the surface morphology, mechanical and wear properties, as well as the corrosion resistance was studied [29]. The principal results were that a deformed structure can be induced, provoking an increase in the hardness in correspondence with the post-processed surface. Additionally, the surface quality was improved and a reduction in the residual porosity was achieved. However, no effect of this innovative post-processing method was investigated on the functional properties of NiTi SLMed parts. For this reason, the present work has the goal of investigating the evolution of the microstructure, which is correlated to the MT, of superelastic NiTi produced by the SLM process.

\section{Experimental}

The as-cast $\mathrm{Ni}_{50.8} \mathrm{Ti}_{49.2}$ (at.\%) ingot (Nitinol Devices \& Components, Inc., Fremont, USA) was gas atomized by TLS Technique GmbH to produce powder, as shown in Figure 1, characterized by a size distribution in the range $25-75 \mu \mathrm{m}$. An SLM system (mod. PXM from Phenix/3D Systems) was used for manufacturing cylindrical samples (10 $\mathrm{mm}$ in diameter and $2 \mathrm{~mm}$ in height); the axis of the cylindrical sample was placed parallel to the SLM building direction, indicated as the $\mathrm{z}$ axis. The process conditions, used for the manufacturing of the samples, are reported in Table 1. 


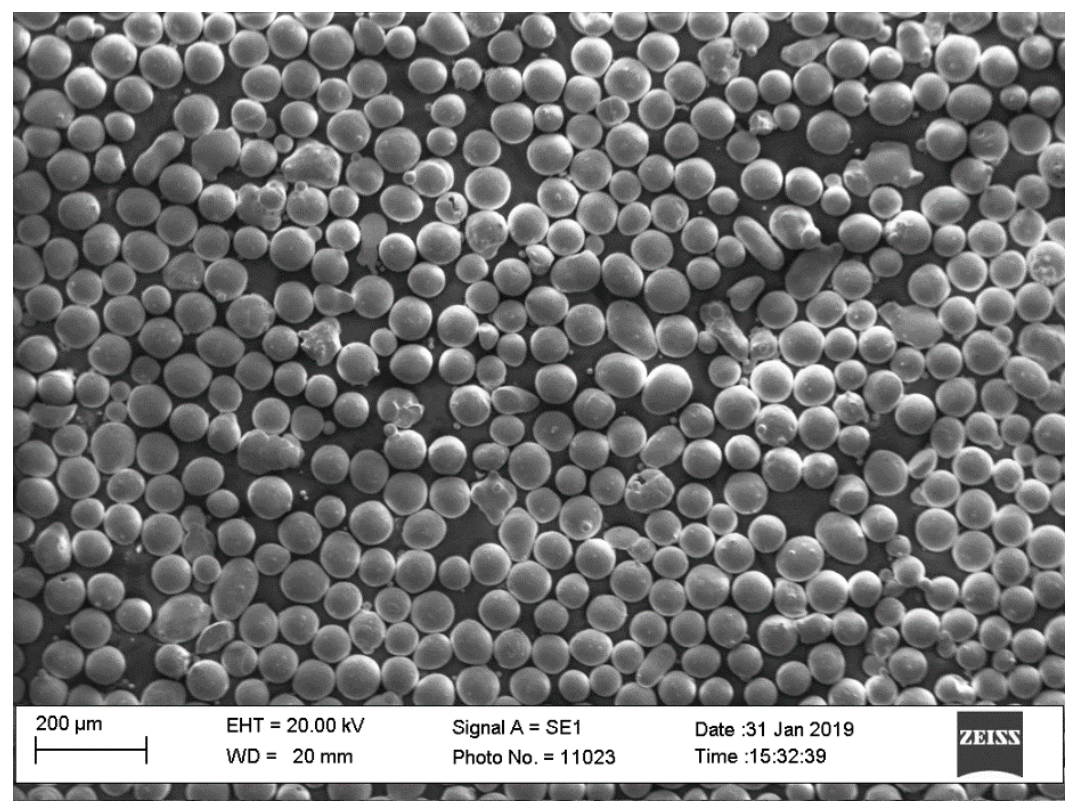

Figure 1. Scanning electron microscope image of the Nitinol powders used for the realization of the selective laser melting (SLM)-built samples.

Table 1. Process parameters used for the manufacturing of the Nitinol samples.

\begin{tabular}{ccccc}
\hline Laser Power & Layer Thickness & Scanning Speed & Hatch Distance & Laser Beam Size \\
\hline $250 \mathrm{~W}$ & $30 \mu \mathrm{m}$ & $1250 \mathrm{~mm} / \mathrm{s}$ & $120 \mu \mathrm{m}$ & $80 \mu \mathrm{m}$ \\
\hline
\end{tabular}

The UNSM process was performed using a tungsten carbide tip ( $2.4 \mathrm{~mm}$ in diameter) in oscillation at $20 \mathrm{kHz}$ [12]. First, a static load of $3 \mathrm{~kg}$ was applied, while the oscillation was characterized by an amplitude of 10 microns and a scanning speed of $2 \mathrm{~m} / \mathrm{min}$. The surface modification treatment was performed on the upper surface of the SLMed cylinder, lying on the $x-y$ plane and perpendicular to the building direction (z axis). Further details of the UNSM process were reported elsewhere [29].

The surface roughness, profile, and mapping were realized by a Keyence VHX-6000 series digital microscope. Then, the samples were cut in order to analyze both the $\mathrm{x}-\mathrm{y}$ and $\mathrm{x}-\mathrm{z}$ plane orientations. First, $x-y$ surfaces were prepared without mounting. Polishing steps were performed, paying attention to remove as little as possible material from the $\mathrm{x}-\mathrm{y}$ surfaces. The $\mathrm{x}-\mathrm{z}$ section was embedded in conductive graphite-loaded mounting resin, and prepared with conventional metallographic polishing techniques (grinding with emery papers and final polishing with diamond suspensions). An additional chemomechanical polishing step was performed with colloidal silica to allow electron back scattered diffraction (EBSD) analyses.

The microstructures of as-built and UNSMed specimens were evaluated through light optical microscopy (OM, mod. Leitz Aristomet) and scanning electron microscopy (W-SEM Leo1430, Zeiss, and FEG-SEM SU70, Hitachi). The texture of the specimens was investigated through electron backscatter diffraction (EBSD), performed at different magnifications, with $20 \mathrm{kV}$ acceleration voltage and step size in the range $0.5-2 \mu \mathrm{m}$. The mechanical properties of the samples were evaluated by Vickers microhardness profiles, performed by using a Leitz Miniload hardness tester, applying a $100 \mathrm{~g}$ load for $10 \mathrm{~s}$. Differential scanning calorimetry (DSC) tests were carried out on specimens (30 mg weight) cut from the full section, which included the modified surface layer and untreated base material. DSC analyses were performed using a Seiko DSC220C with a heating/cooling rate of 10 ${ }^{\circ} \mathrm{C} /$ min within a temperature range of $-100{ }^{\circ} \mathrm{C}$ to $100{ }^{\circ} \mathrm{C}$; three complete cycles were performed for each sample. X-ray diffraction patterns were collected by a diffractometer (Panalytical X'Pert Pro) using $\mathrm{Cu} \mathrm{K} \alpha$ radiation, operating at $40 \mathrm{kV}$ and $30 \mathrm{~mA}$ in the $20^{\circ}-100^{\circ}$ 2theta range. The patterns were 
acquired at temperatures of $-60^{\circ} \mathrm{C}$ and $60^{\circ} \mathrm{C}$, temperatures selected after DSC results in order to ensure complete phase transformation into martensite or austenite, respectively.

\section{Results and Discussion}

Figure 2 shows the macrograph of the sample, partially post-processed and partially left in the as-built condition, and the corresponding 3D profilometric measurements. The as-built surface indicates the presence of irregularities, depending on the balling effect, due to the melting of the powder and followed by solidification. Preferential direction can be seen, which depends on the scanning direction adopted during the last processed layer. Evidence of residual traces associated with the laser scanning lines on the UNSMed surface can be found, but the plastic deformation process limited the difference between peaks and valleys in the roughness profile, according to the color bar. Moreover, the roughness values were not only reduced but also evened out, to the 3D roughness profiles, and the average roughness varied from $12 \mu \mathrm{m}$ down to $9 \mu \mathrm{m}$ through the UNSM processing.
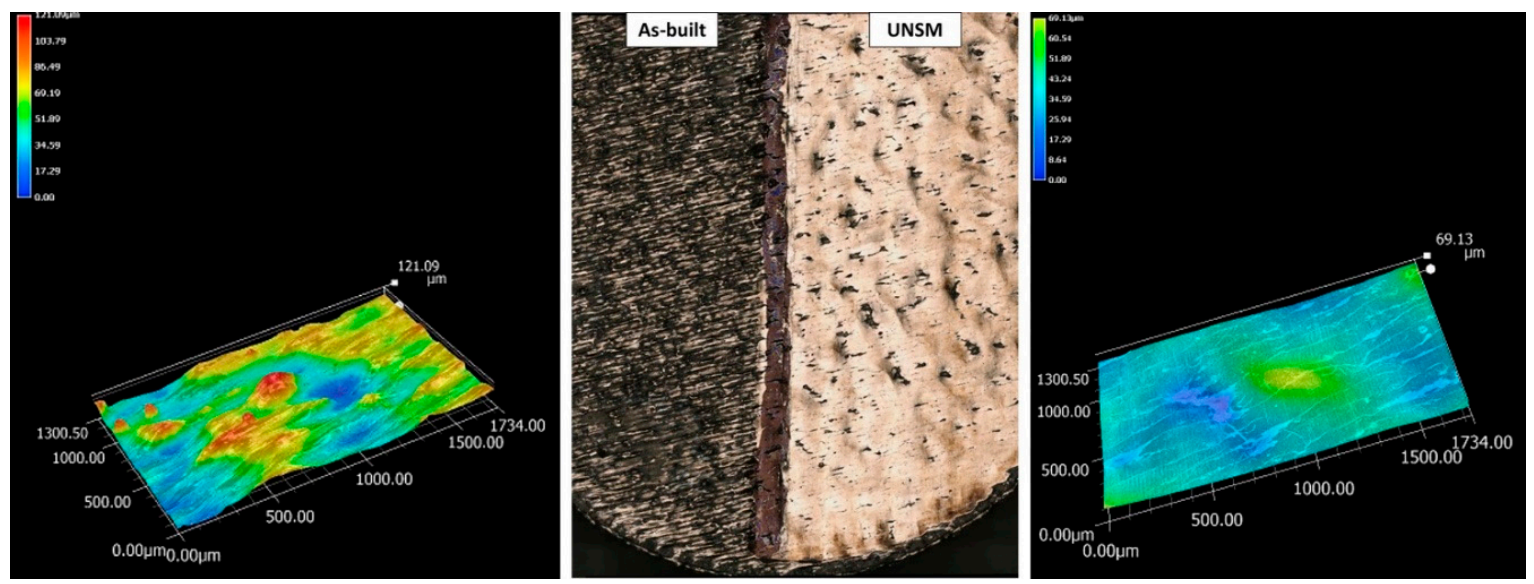

Figure 2. Macrograph of the sample, showing on the left the as built surface and on the right the UNSMed surface with the corresponding 3D profilometry measurements.

In Figure 3, micrographs at two magnifications, acquired with OM, are presented of the UNSMed and as-built surfaces. Low magnification micrographs are representative of the porosities present just near the upper surface of the samples. A comparison of Figure $3 a, b$ reports the partial occlusion of the pores, placed in the $x-y$ view, due to the plastic deformation induced by the UNSM process [29]. In particular, the post-processing can significantly reduce the pore size, as can be seen from the porosity evolution highlighted from the circles in Figure 3a,b. At higher magnifications, the variation in the microstructure can be observed. Figure $3 \mathrm{~d}$ shows the microstructure of the as-built material: the traces of the liquid pools provoked by laser along the scanning direction are clearly recognizable, and are characterized by bright features at melt pool boundaries. After the UNSM process, a squared pattern (see blue colored lines in Figure 3c), of approximately $120 \mu \mathrm{m}$ edge size, can be appreciated, which mimics the texture of the material due to the $90^{\circ}$ building strategy. This effect is due to local plastic deformation, which mitigates typical features of solidification melt pools (faint segregations at melt pools boundaries), and enhances underlying texture effects. Further analysis at higher magnifications, performed by SEM, can better clarify the microstructural modifications. 


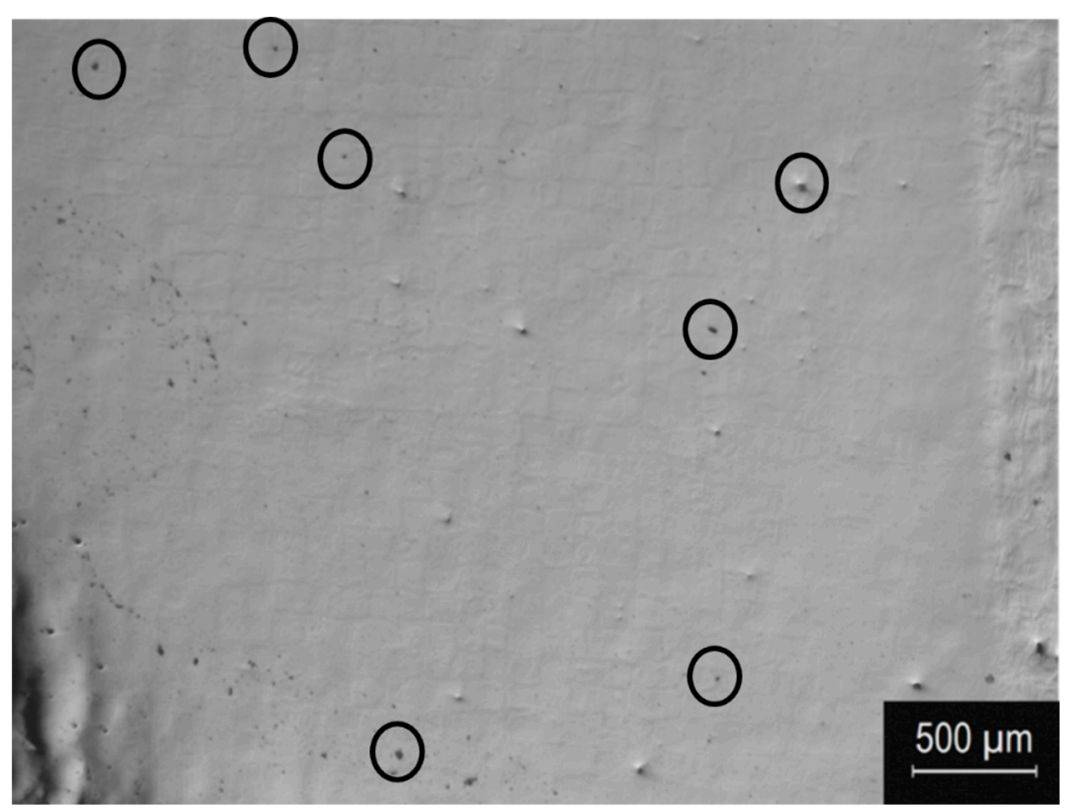

(a)

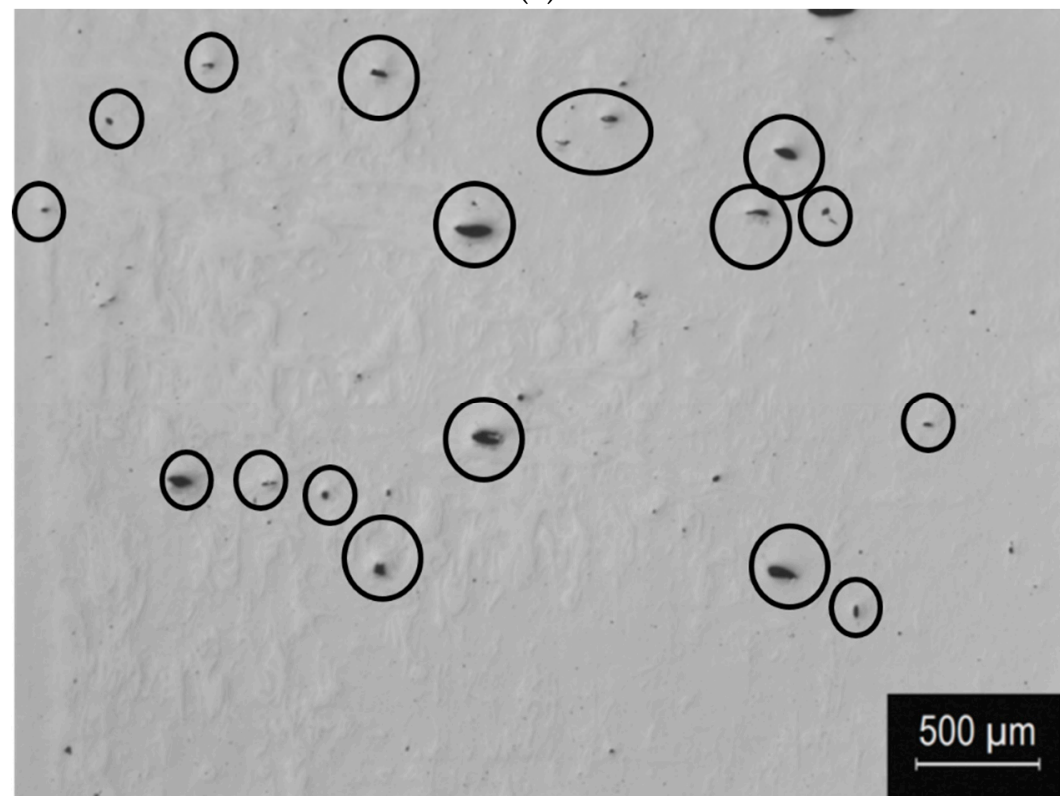

(b)

Figure 3. Cont. 


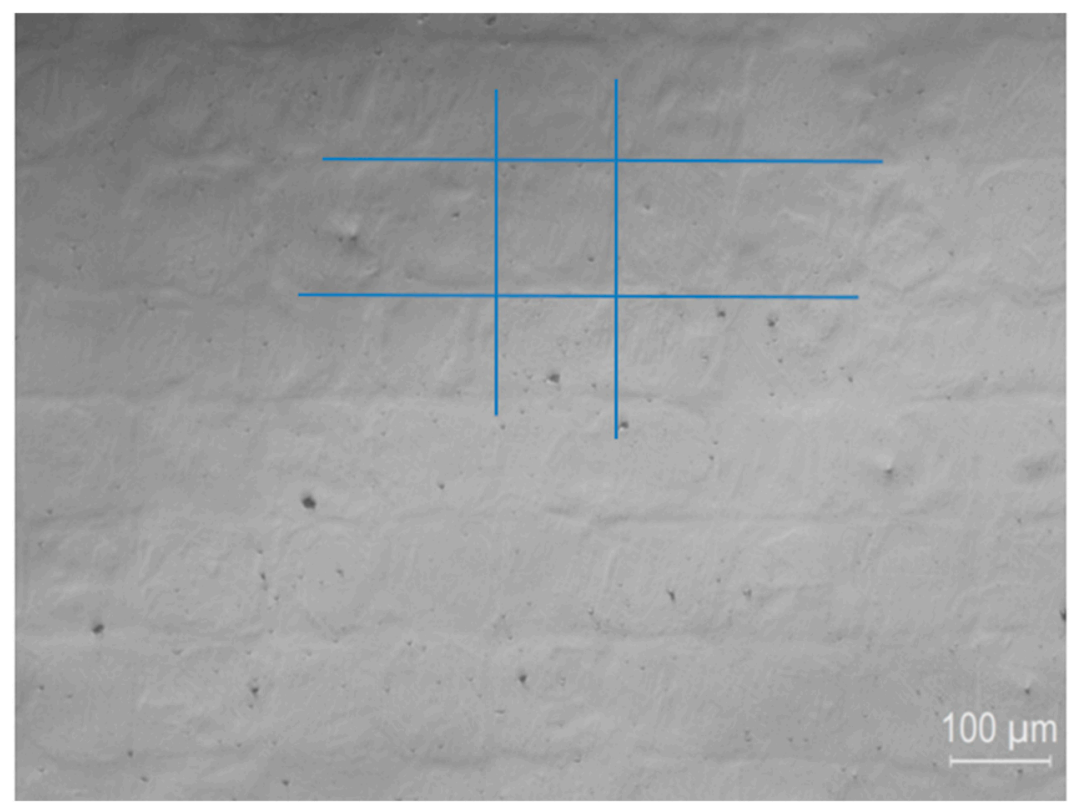

(c)

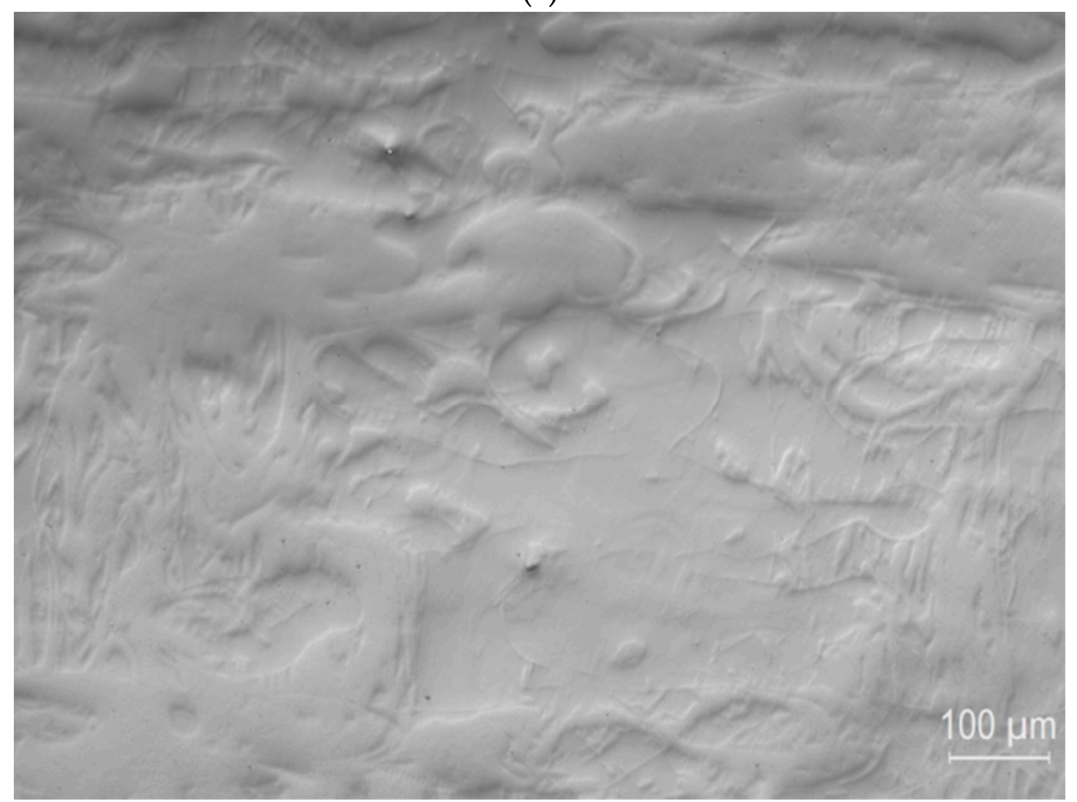

(d)

Figure 3. Micrographs showing planar $x-y$ views of the UNSMed $(\mathbf{a}-\mathbf{c})$ and the as-built surfaces $(\mathbf{b}-\mathbf{d})$, acquired by optical microscope at two magnifications.

Figure 4 shows the SEM micrographs acquired using backscattered electrons (BSE) in the planar $\mathrm{x}-\mathrm{y}$ view of the UNSMed and as-built surfaces. Figure 4a reports the surfaces, before (right side) and after (left side) the UNSM process: backscatter contrast is more pronounced in the as-built side, while the UNSM side shows far less evident contrast. Three regions for each condition were analyzed by energy dispersive spectroscopy (EDS) and no compositional difference was observed. Elemental analysis is reported in Table 2. As expected, the plastic deformation did not provoke any loss of $\mathrm{Ni}$ or Ti elements or oxidation. Moreover, the variability in the composition was slightly limited and an equiatomic Ni:Ti ratio was maintained. Figure $4 b, c$ shows the surfaces at higher magnification. The UNSMed surface is characterized by the squared footprints, previously observed in Figure $2 \mathrm{~d}$, with relatively low contrast. On the contrary, the SEM image of the as-built surface indicates the presence of areas with different BSE contrast, evidencing the presence of microstructural features correlated to the 
melt pool morphology and to incomplete melting of some powders, too. The strong contrast of these areas was mainly due to microstructural differences. EDS measurements were performed on the light and dark areas, respectively indicated as point 7 and 8 in Table 3 , and the resulting Ni:Ti ratios do not indicate any significant compositional modification.

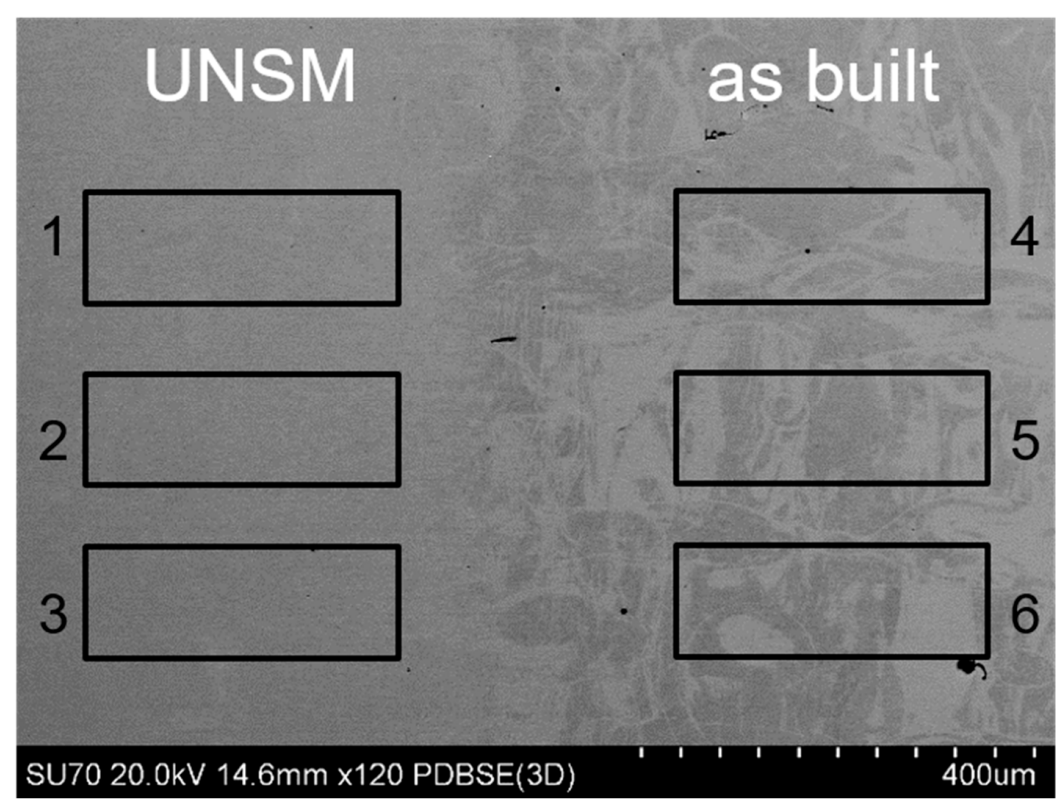

(a)

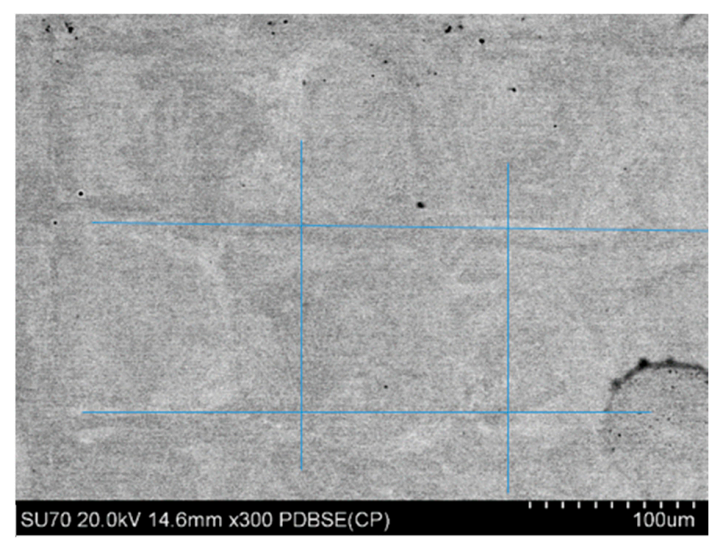

(b)

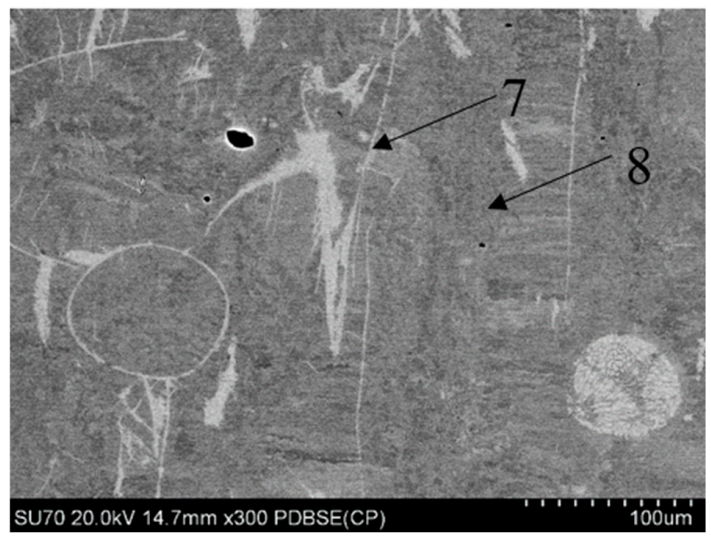

(c)

Figure 4. BSE-SEM micrographs in the $x-y$ view: surface containing the border between depicting the UNSMed and the initial surfaces (a); higher magnification of the UNSMed (b) and as-built surface (c). 
Table 2. Quantitative compositional results from EDS measurements, performed in the planar x-y view. The indication regarding the localization of the region of measurement is indicated in Figure $4 \mathrm{a}, \mathrm{c}$. For all measurements, an average $0.3 \%$ sigma was obtained.

\begin{tabular}{ccc}
\hline Sites & Ti Content (at. \%) & Ni Content (at. \%) \\
\hline 1 & 49.88 & 50.12 \\
2 & 50.25 & 49.75 \\
3 & 49.97 & 50.03 \\
4 & 50.01 & 49.99 \\
5 & 50.07 & 49.93 \\
6 & 49.66 & 50.34 \\
7 & 49.76 & 50.24 \\
8 & 49.40 & 50.60 \\
\hline
\end{tabular}

BSE-SEM observations were also performed along the building direction, indicated as the $x-z$ view. In Figure $5 a$, the $x-z$ view of the UNSMed sample is shown. It can be seen that the upper portion of the NiTi sample is characterized by a different microstructure with respect to the underlying material, representing both as-built and UNSMed material. A compositional profile was performed (see the region from 9 to 15 of Figure $4 \mathrm{a}$ ) and the corresponding results are listed in Table 3. As expected, no compositional modification was observed along the building direction. On the contrary, the plastic work of the USNM process induced clear modification of the microstructure of the SLMed NiTi alloy. Figure $5 b, c$ depicts the microstructure obtained by the surface modification process and a reference one. The typical microstructure of AMed parts, in which small overlapping liquid pools are due to the layer by layer building strategy, cannot be seen in the UNSMed portion. In fact, plastic deformation and amorphization [28] induced by UNSM hindered the BSE texture sensitivity; moreover, lamellar features, grouped in colonies of similar orientation, can be observed, possibly deformation bands or stress-induced martensite. Moving far from the upper surface, the as-built material is characterized by a microstructure similar to that reported in Figure 3c, in which the presence of the adjacent liquid pools, due to the laser traces, and related inhomogeneities in BSE contrast can be detected. No other differences were observed between the as-built and UNSMed material.

Table 3. Compositional results from EDS measurements, performed in the $x-z$ view. The indication regarding the localization of the region of measurement is indicated in Figure 5a. For all measurements average $0.3 \%$ sigma was obtained.

\begin{tabular}{ccc}
\hline Sites & Ti Content (at. \%) & Ni Content (at. \%) \\
\hline 9 & 48.84 & 51.16 \\
\hline 10 & 49.21 & 50.79 \\
\hline 11 & 49.41 & 50.79 \\
\hline 12 & 48.89 & 51.11 \\
\hline 13 & 49.57 & 50.43 \\
\hline 14 & 49.12 & 50.88 \\
\hline 15 & 49.06 & 50.94 \\
\hline
\end{tabular}




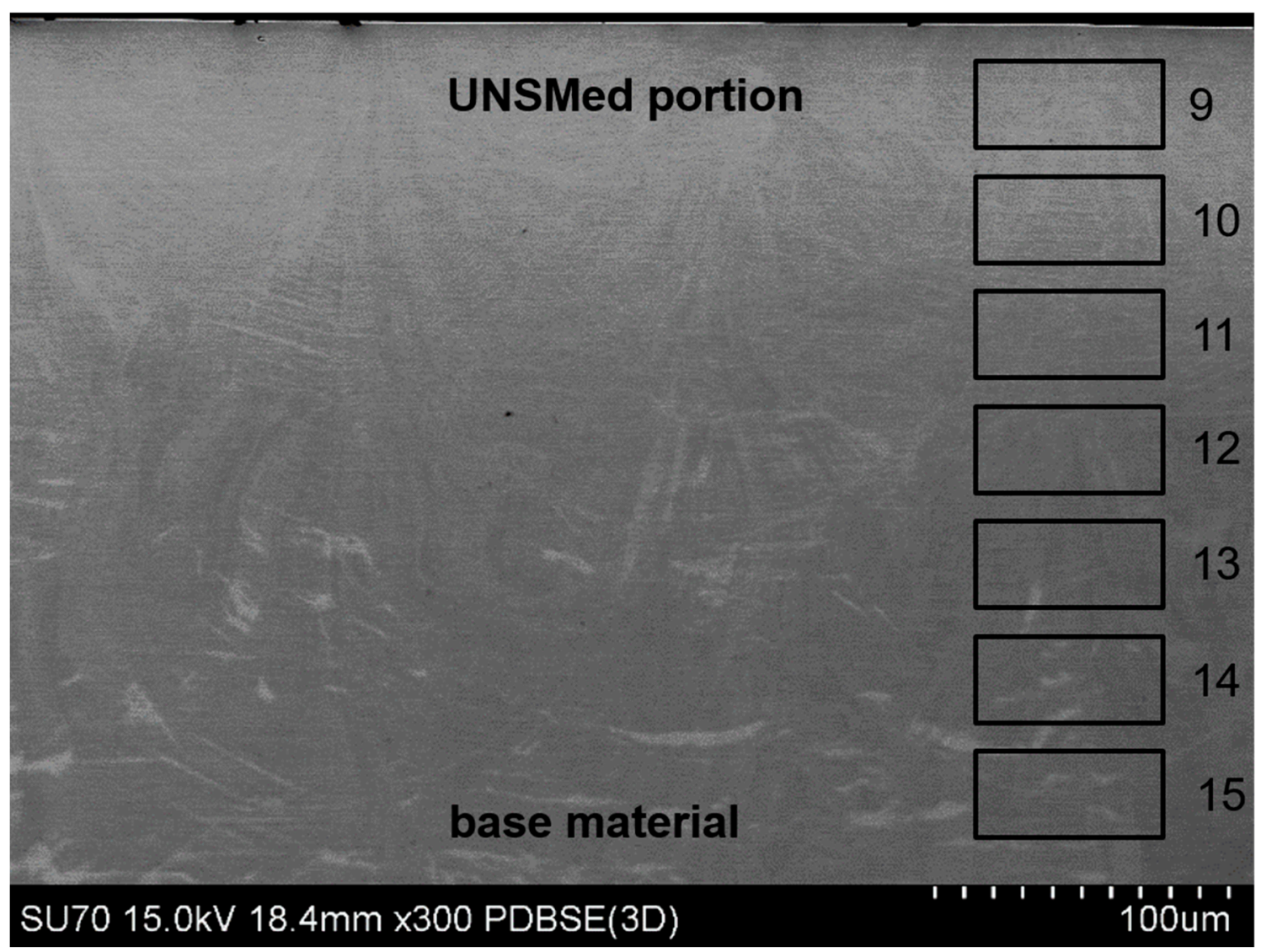

(a)

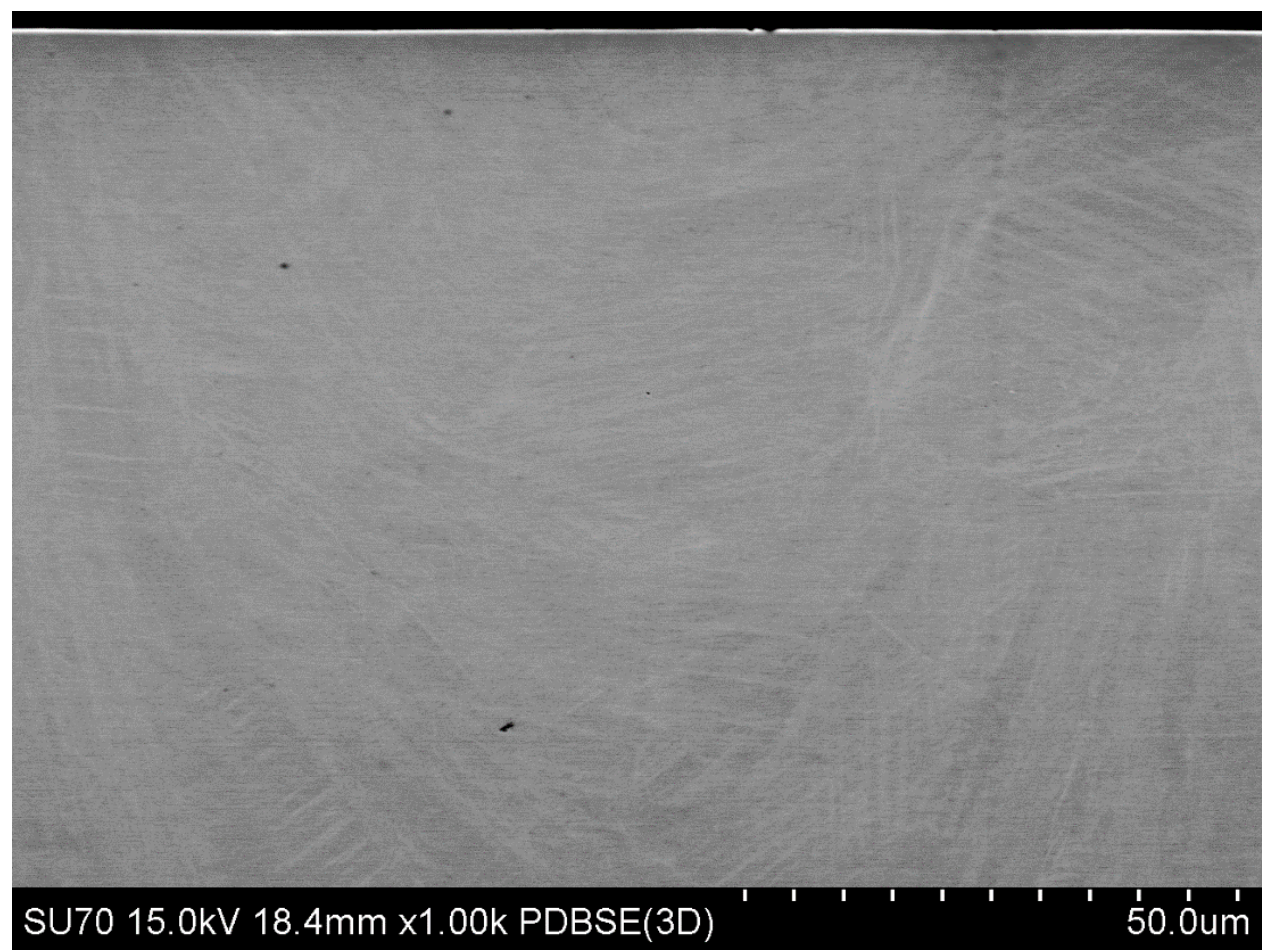

(b)

Figure 5. Cont. 


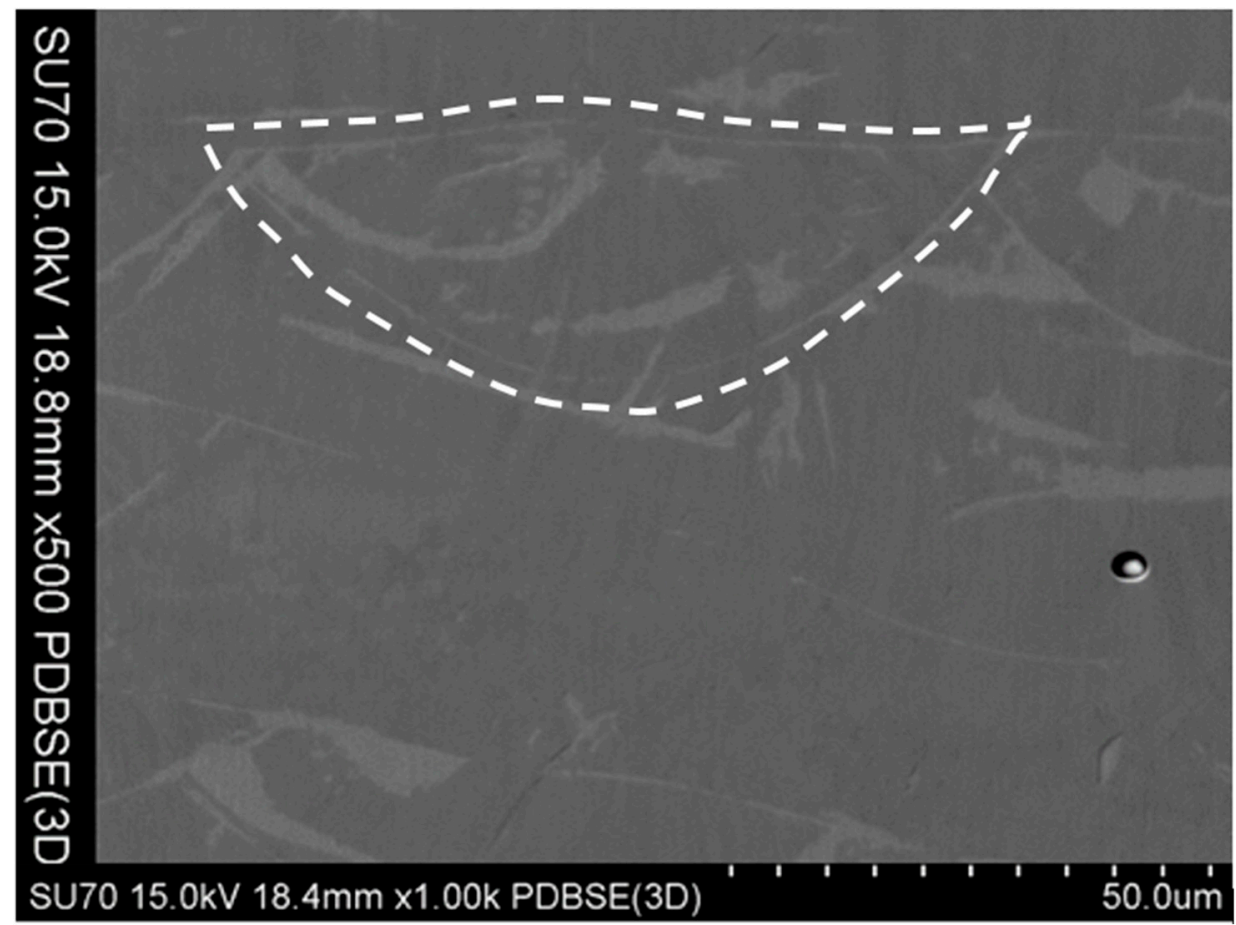

(c)

Figure 5. Back scattered electron (BSE)-SEM image in the $\mathrm{x}-\mathrm{z}$ view of the UNSMed sample (a), showing the regions for the EDS compositional profile; magnifications of the UNSMed portion (b) and the base material, with an highlighted melt pool boundary (c).

Figure 6 shows the EBSD analysis performed on the $\mathrm{x}-\mathrm{z}$ view for both of the conditions. After the rapid solidification characteristic of the SLM process, the structure contained elongated grains, orientated along the building direction (see Figure $6 \mathrm{a}$ ). The material was characterized by a weak texture, with (001) aligned with the building direction. The UNSM process can cause severe plastic deformation to the surface layers, leading to lattice distortion and crystal defects, which significantly weaken Kikuchi patterns. Consequently, a wide non-indexed area appeared in the treated region, as shown in Figure 6b. Additional unsolved pixels inside as-built material seem to be related to locally stress-induced martensite (SIM) or to martensite induced by small chemical composition variations. The local plastic deformation can be estimated at a depth below $200 \mu \mathrm{m}$. In Figure 7, pole figures of the as-built sample are shown; no intense preferential texture can be observed. This can be associated with the selected process condition not able to induce strong preferential crystal orientations during the SLM process [11,18].

Due to the microstructure modification induced by the UNSM process, a sensible variation in mechanical behavior can be expected. The evolution of the microhardness is plotted in Figure 8 . The UNSM-treated sample exhibited an increase in microhardness values on the upper surface up to $470 \mathrm{HV}$, which can be attributed to the plastic deformation induced by the postprocessing. The effect of the UNSM process disappeared at a penetration of approximately $750 \mu \mathrm{m}$ from the surface, reaching around $240 \mathrm{HV}$ in microhardness in the as-built material. 


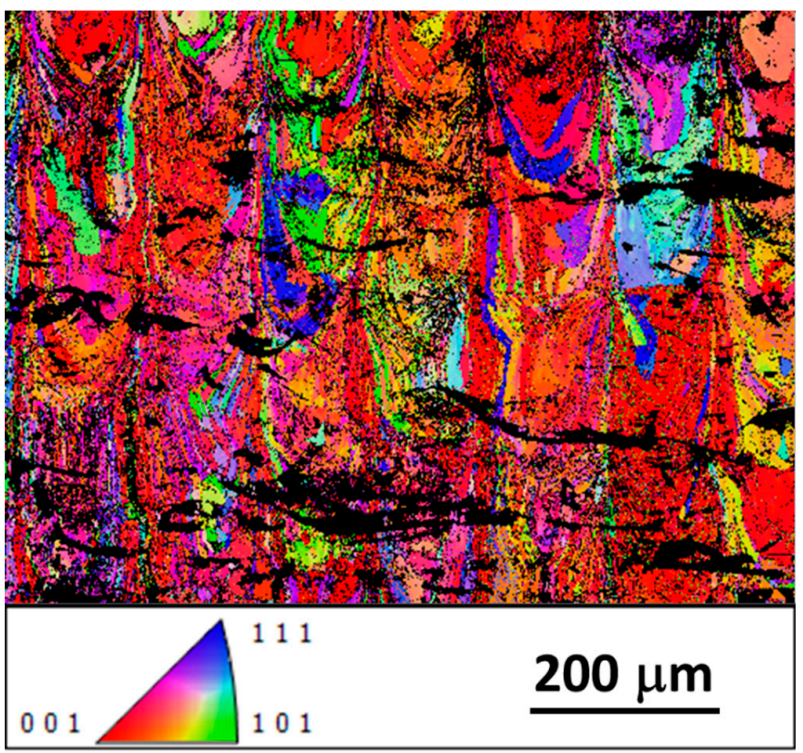

(a)

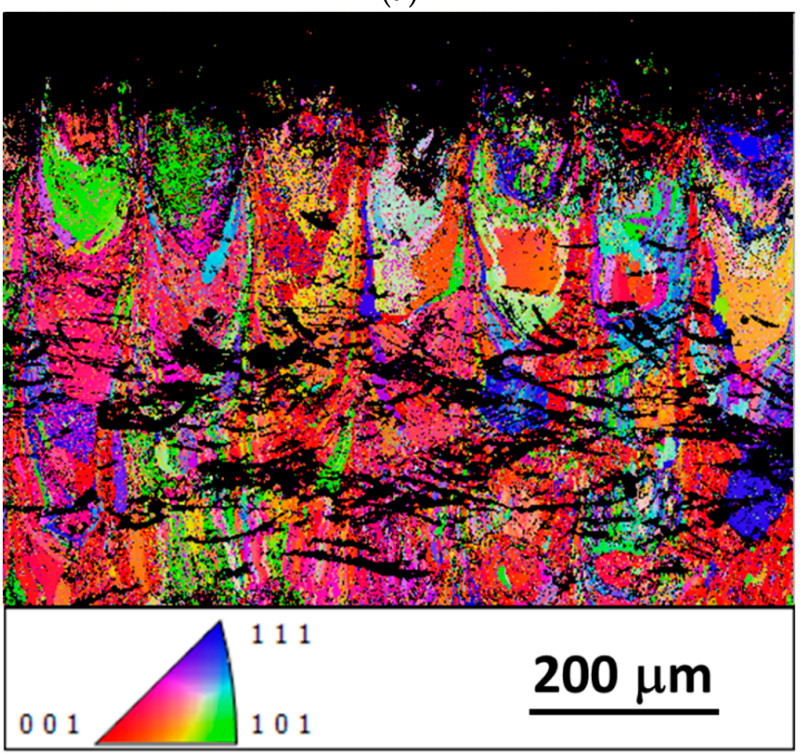

(b)

Figure 6. Electron backscatter diffraction (EBSD) analysis performed in the $x-z$ view of the two conditions: as-built (a) and UNSMed samples (b), according to orientation map micrograph related to the building direction.

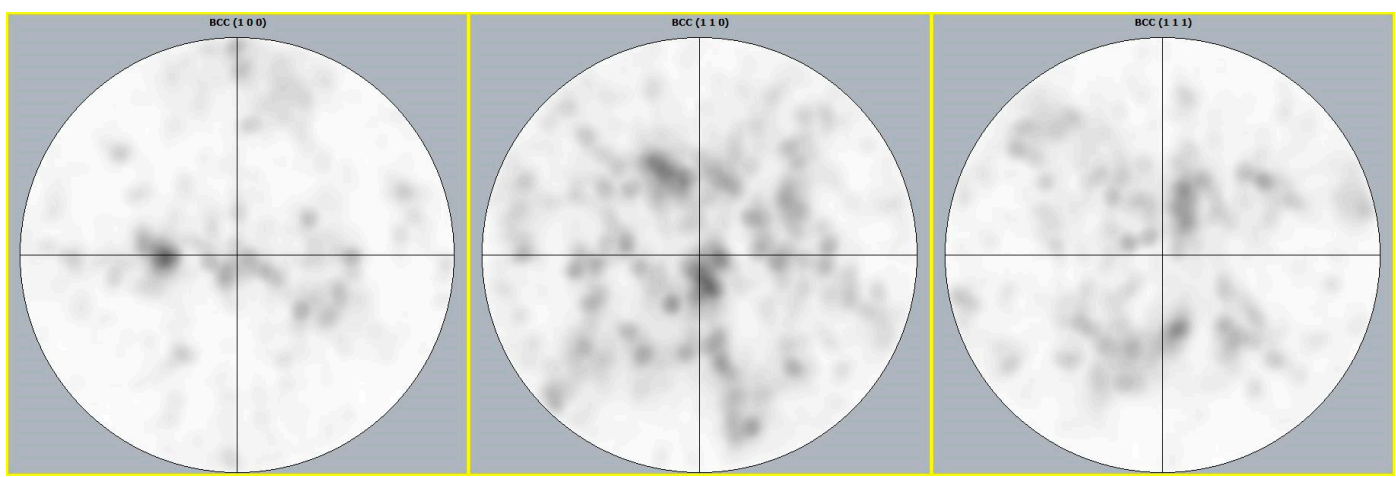

Figure 7. Pole figures of the as-built sample. 


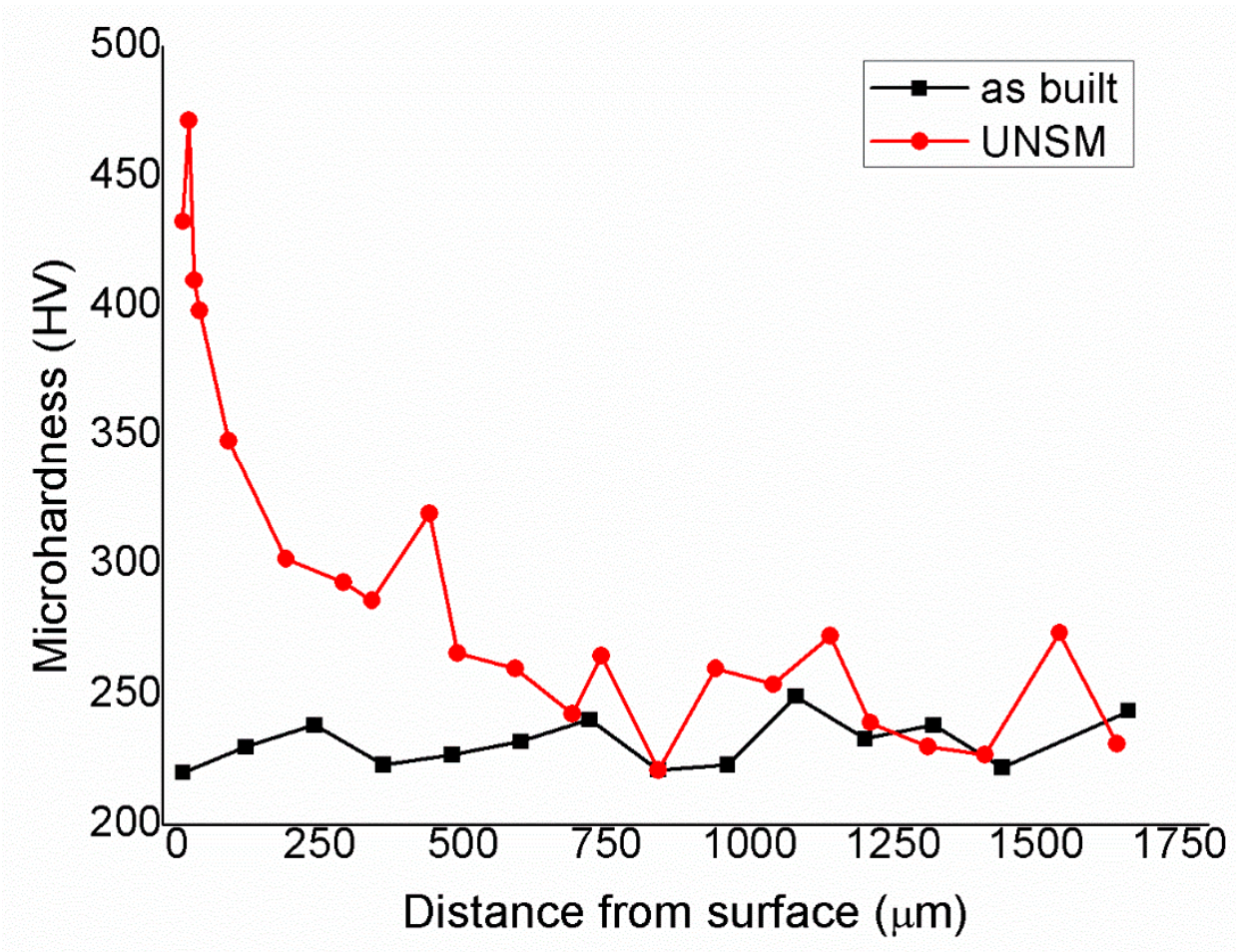

Figure 8. Microhardness profiles of the as-built and UNSMed samples.

This increase in hardness could depend on high stress values generated during the UNSM process, able to provoke relevant plastic deformation and therefore induce cold working. The stress applied during the UNSM process is higher than the stress required for mechanically inducing the martensite (usually in the range of $400-500 \mathrm{MPa}$ ), because it is able to induce partial cold working on the upper surface of the NiTi sample.

The MT of the samples in both of the conditions, as-built and UNSMed, was investigated by coupling DSC and XRD analyses. According to Figure 8, there was not a noticeable difference in MT behavior between the DSC samples. This is quite reasonable, as the USNM process does not influence a thick portion of the NiTi sample but it is confined in a limited depth [29], as shown by Figure 8. The MT is stable upon three complete thermal cycles and the alloy is fully superelastic at body temperature. Table 4 reports the values of the transformation temperatures and the transformation enthalpies, measured from the DSC scans on the third cycle. Due to the unclear ending point of direct transformation, values of Mf and transformation enthalpies are affected by measurement uncertainty. Nethertheless, the transformation temperatures did not seem to be influenced by the sample condition. The observed temperatures shift was very limited and did not suggest any significant alterations in the material properties.

Table 4. Transformation temperatures and enthalpies during the MT of as-built and UNSMed samples.

\begin{tabular}{ccccccccc}
\hline Samples & $\mathbf{H}_{\mathbf{M} \rightarrow \mathbf{A}}(\mathrm{J} / \mathbf{g})$ & $\mathbf{A s}\left({ }^{\circ} \mathbf{C}\right)$ & $\mathbf{A p}\left({ }^{\circ} \mathbf{C}\right)$ & $\mathbf{A f}\left({ }^{\circ} \mathbf{C}\right)$ & $\mathbf{H}_{\mathbf{A} \rightarrow \mathbf{M}}(\mathrm{J} / \mathbf{g})$ & $\mathbf{M s}\left({ }^{\circ} \mathbf{C}\right)$ & $\mathbf{M p}\left({ }^{\circ} \mathbf{C}\right)$ & $\mathbf{M f}\left({ }^{\circ} \mathbf{C}\right)$ \\
\hline As-built & 18.7 & -18 & 20 & 40 & 19.5 & 14 & -8 & -46 \\
\hline UNSM & 19 & -16 & 18 & 39 & 17.9 & 13 & -11 & -40 \\
\hline
\end{tabular}

Moreover, the transformation enthalpies remained rather constant in the range 18-19 J/g after the USNM process, which is in good agreement with the NiTi reference [1]. This indicates that the modification was confined only to the machined surface and the massive NiTi did not suffer any significant modifications, not only in the chemical composition but also in the microstructure, which has high sensibility to plastic deformation [30]. 
Figure 10a,b depict the XRD spectra, performed at temperatures of $-60^{\circ} \mathrm{C}$ and $60{ }^{\circ} \mathrm{C}$, of as-built and UNSMed surfaces, respectively. The temperatures were selected in order to control the evolution of the microstructure after the complete MT from austenite $\left(+60^{\circ} \mathrm{C}\right)$ into martensite $\left(-60{ }^{\circ} \mathrm{C}\right)$. The as-built sample showed a complete MT; a B2 austenite phase was identified at high temperature, while the B19' structure was detected at low temperature. No evident residual austenite was found at $-60{ }^{\circ} \mathrm{C}$ in the as-built sample. This analysis is in good agreement with the DSC investigation of Figure $9 \mathrm{~b}$.

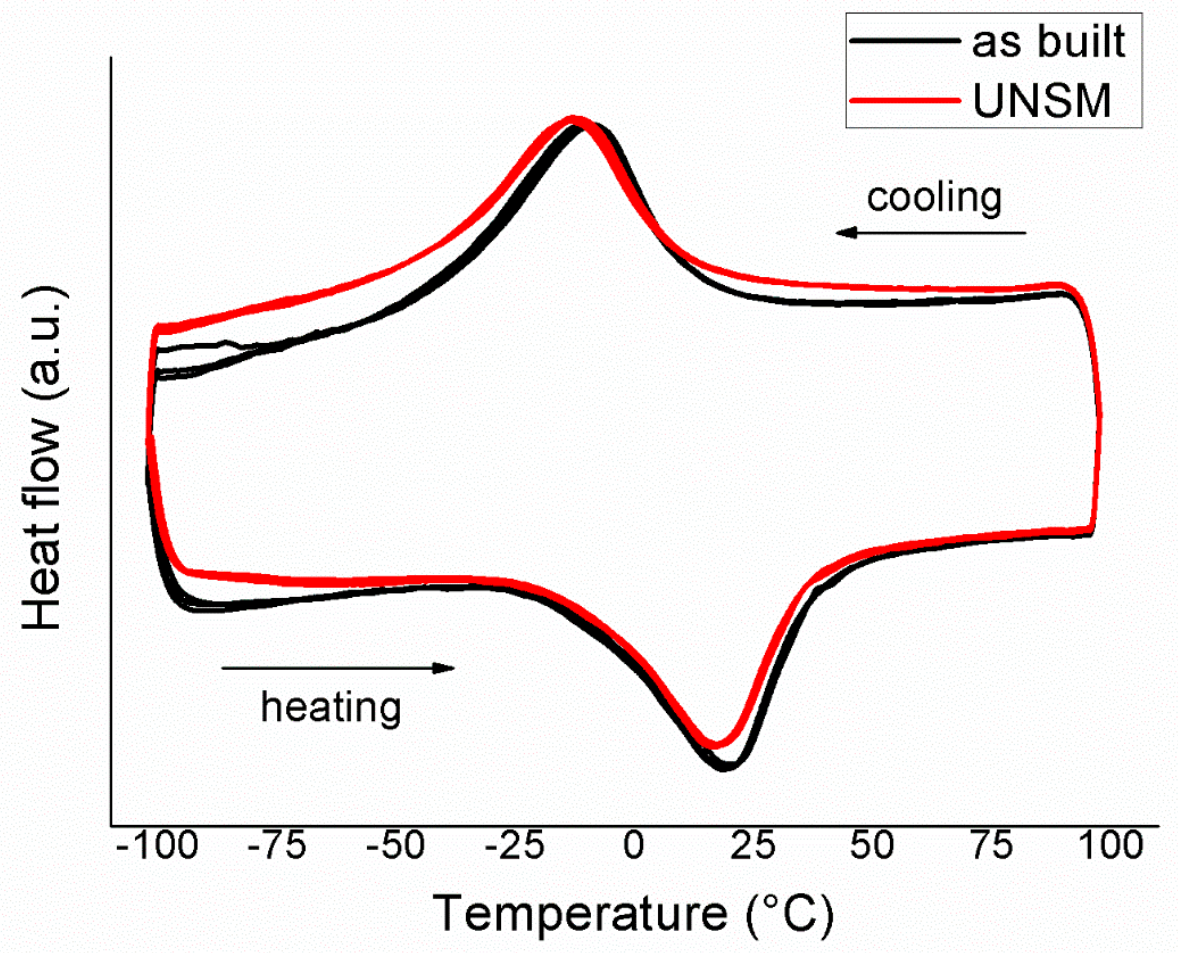

Figure 9. DSC scans of the as-built and UNSMed samples.

On the contrary, the USNM-treated sample showed a different behaviour: at high temperature, the sample had a B2 austenitic structure, according to the DSC measurement. The main difference with the as-built sample is that the B2 peaks were far broader, indicating a highly defective austenitic structure and possibly also stress-induced martensite in the microstructure. The relative intensities of the (110), (002), and (211) austenitic peaks were similar in the two conditions, indicating that no abrupt change in the texture occurred. Few modifications in the microstructure were detected upon temperature varyiation, and consisted in a slight increase of the humps in the martensite peak angular regions. This means that the plastic deformation induced by the USNM process can induce a cold working sufficient to mostly suppress the MT in the first few microns from the upper surface. However, the degree of plastic deformation associated with the UNSM process performed on the investigated sample induced a broadening effect of the B2 peak (110), as shown in Figure 10b, but no complete surface amorphization, as reported in the literature [28]. This is an important result, because it can be stated that the UNSM process can be designed for the occlusion of the pores, improving the surface quality and limiting the lattice distortion for minimizing the cristallinity alteration. 


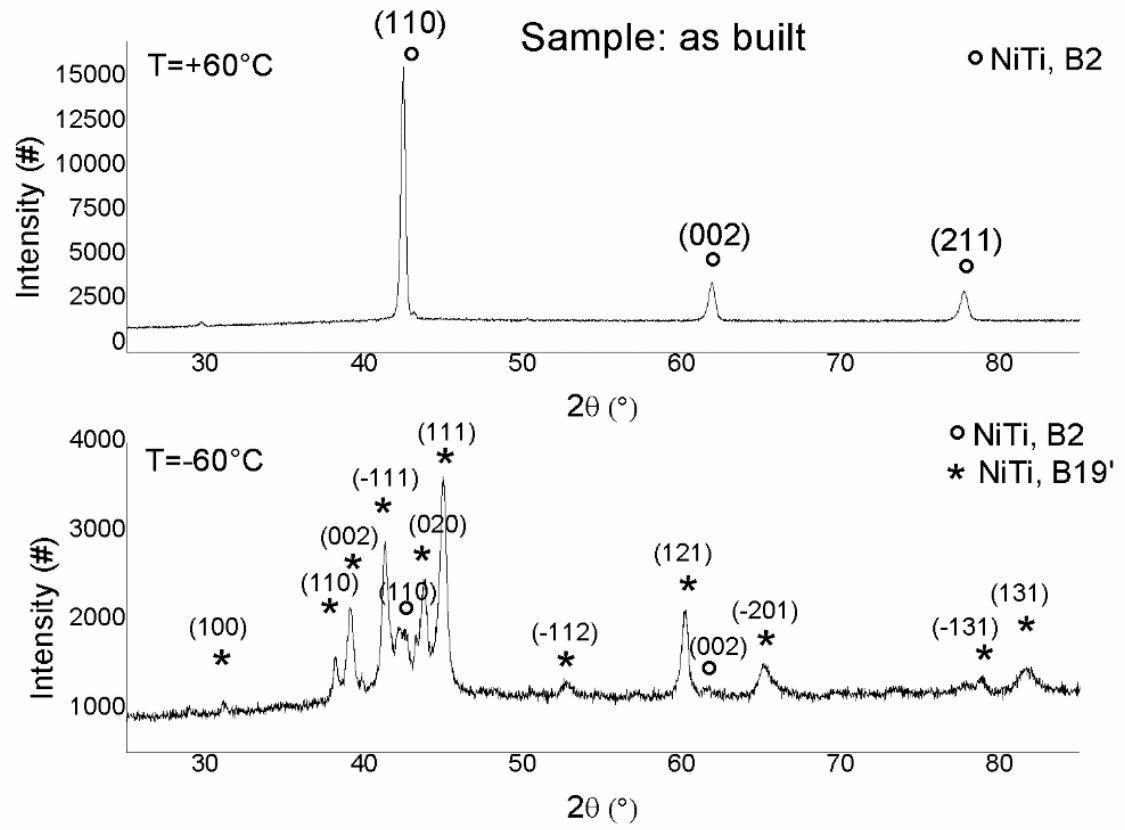

(a)

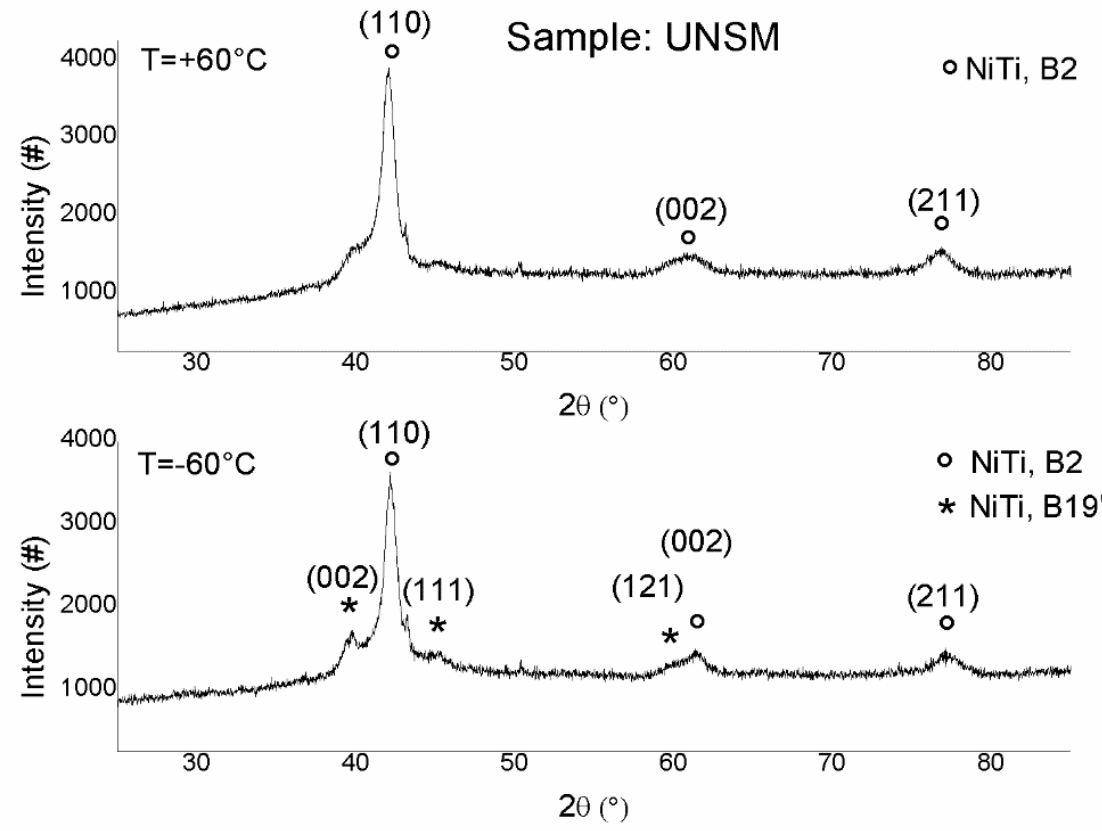

(b)

Figure 10. XRD patterns at two temperatures $\left(-60^{\circ} \mathrm{C}\right.$ and $\left.60^{\circ} \mathrm{C}\right)$ of as-built (a) and UNSMed (b) surfaces.

\section{Conclusions}

The effect of an advanced finishing process, namely, ultrasonic nano-crystal surface modification, on the microstructure and martensitic transformation of an SLMed Nitinol sample was investigated. The following conclusions can be highlighted:

(1) The UNSM process can offer benefits in the post-processing of AM products, being able to occlude surface pores and slightly decrease the roughness; 
(2) Due to the mechanical energy deposited on the Nitinol sample, the texture induced by the SLM process varied after the UNSM treatment without any compositional variation;

(3) The local plastic deformation suppressed the martensitic transformation at a depth estimated to be below $200 \mu \mathrm{m}$ by EBSD analysis, due to the plastic deformation induced by the post-processing;

(4) The microhardness profile indicated a deeper variation in the mechanical properties, down to 750 $\mu \mathrm{m}$;

(5) In this work, the microstructure obtained on the upper surface after the post-processing contained both austenite and martensite, but NiTi amorphization was avoided. This is a different result from literature. As a consequence, the selection of the main parameters of the ultrasonic nano- changes;

(6) The improvement of the mechanical properties of the surface could enhance the fatigue behavior of the post-processed parts.

Author Contributions: C.A.B. and P.B. performed the characterizations and wrote the paper. M.N. and N.S.M. manufactured the samples and performed some characterizations. A.A. and M.J.M. performed the experiments on the post-processing. M.E. and A.T. wrote the paper. All the authors participated to the paper review.

Funding: This research was founded by Accordo Quadro CNR/Regione Lombardia grant number 3866 at $17 / 07 / 2015$ in the framework of the project FHfFC.

Conflicts of Interest: The authors declare no conflicts of interest.

\section{References}

1. Funakubo, H. Shape Memory Alloys; Gordon and Breach Science Publishers: Amsterdam, The Netherlands, 1987.

2. Nishida, M.; Wayman, C.M.; Honma, T. Precipitation processes in near-equiatomic TiNi shape memory alloys. Met. Mater. Trans. A 1986, 17, 1505-1515. [CrossRef]

3. Elahinia, M.; Moghaddam, N.S.; Andani, M.T.; Amerinatanzi, A.; Bimber, B.A.; Hamilton, R.F. Fabrication of NiTi through additive manufacturing: A review. Prog. Mater. Sci. 2016, 83, 630-663. [CrossRef]

4. Van Humbeeck, J. Additive Manufacturing of Shape Memory Alloys. Shap. Mem. Superelast. 2018, 4, 309-312. [CrossRef]

5. Dadbakhsh, S.; Speirs, M.; Van Humbeeck, J.; Kruth, J.-P. Laser additive manufacturing of bulk and porous shape-memory NiTi alloys: From processes to potential biomedical applications. Mrs Bull. 2016, 41, 765-774. [CrossRef]

6. Nematollahi, M.; Toker, G.; Saghaian, S.E.; Salazar, J.; Mahtabi, M.; Benafan, O.; Karaca, H.; Elahinia, M. Additive Manufacturing of Ni-Rich NiTiHf20: Manufacturability, Composition, Density, and Transformation Behavior. Shap. Mem. Superelast. 2019, 5, 113-124. [CrossRef]

7. Saghaian, S.E.; Moghaddam, N.S.; Nematollahi, M.; Saedi, S.; Elahinia, M.; Karaca, H.E. Mechanical and shape memory properties of triply periodic minimal surface (TPMS) NiTi structures fabricated by selective laser melting. Biol. Eng. Med. 2018, 3, 1-7.

8. Wang, C.; Tan, X.; Du, Z.; Chandra, S.; Sun, Z.; Lim, C.; Tor, S.; Lim, C.; Wong, C. Additive manufacturing of NiTi shape memory alloys using pre-mixed powders. J. Mater. Process. Technol. 2019, 271, 152-161. [CrossRef]

9. Zhou, Q.; Hayat, M.D.; Chen, G.; Cai, S.; Qu, X.; Tang, H.; Cao, P. Selective electron beam melting of NiTi: Microstructure, phase transformation and mechanical properties. Mater. Sci. Eng. A 2019, 744, 290-298. [CrossRef]

10. Hamilton, R.F.; Bimber, B.A.; Palmer, T.A. Correlating microstructure and superelasticity of directed energy deposition additive manufactured Ni-rich NiTi alloys. J. Alloy. Compd. 2018, 739, 712-722. [CrossRef]

11. Saedi, S.; Moghaddam, N.S.; Amerinatanzi, A.; Elahinia, M.; Karaca, H.E. On the effects of selective laser melting process parameters on microstructure and thermomechanical response of Ni-rich NiTi. Acta Mater. 2018, 144, 552-560. [CrossRef]

12. Ahadi, A.; Dadbakhsh, S.; Kruth, J.-P.; Wang, X.; Van Baelen, S.; Van Humbeeck, J.; Speirs, M. On the Transformation Behavior of NiTi Shape-Memory Alloy Produced by SLM. Shap. Mem. Superelast. 2016, 2, 310-316. 
13. Saedi, S.; Turabi, A.S.; Andani, M.T.; Haberland, C.; Karaca, H.; Elahinia, M. The influence of heat treatment on the thermomechanical response of Ni-rich NiTi alloys manufactured by selective laser melting. J. Alloy. Compd. 2016, 677, 204-210. [CrossRef]

14. Sam, J.; Franco, B.; Ma, J.; Karaman, I.; Elwany, A.; Mabe, J. Tensile actuation response of additively manufactured nickel-titanium shape memory alloys. Scr. Mater. 2018, 146, 164-168. [CrossRef]

15. Moghaddam, N.S.; Saghaian, S.E.; Amerinatanzi, A.; Ibrahim, H.; Li, P.; Toker, G.P.; Karaca, H.E.; Elahinia, M. Anisotropic tensile and actuation properties of NiTi fabricated with selective laser melting. Mater. Sci. Eng. A 2018, 724, 220-230. [CrossRef]

16. Shiva, S.; Palani, I.; Mishra, S.; Paul, C.; Kukreja, L. Investigations on the influence of composition in the development of Ni-Ti shape memory alloy using laser based additive manufacturing. Opt. Laser Technol. 2015, 69, 44-51. [CrossRef]

17. Mahmoudi, M.; Tapia, G.; Franco, B.; Ma, J.; Arroyave, R.; Karaman, I.; Elwany, A. On the printability and transformation behavior of nickel-titanium shape memory alloys fabricated using laser powder-bed fusion additive manufacturing. J. Manuf. Process. 2018, 35, 672-680. [CrossRef]

18. Bormann, T.; Müller, B.; Schinhammer, M.; Kessler, A.; Thalmann, P.; De Wild, M. Microstructure of selective laser melted nickel-titanium. Mater. Charact. 2014, 94, 189-202. [CrossRef]

19. Kaynak, Y.; Kitay, O. The effect of post-processing operations on surface characteristics of 316L stainless steel produced by selective laser melting. Addit. Manuf. 2019, 26, 84-93. [CrossRef]

20. Namatollahi, M.; Jahadakbar, A.; Mahtabi, M.J.; Elahinia, M. Additive manufacturing (AM). In Metals for Biomedical Devices, 2nd ed.; Woodhead Publishing: Cambridge, UK, 2019; pp. 331-353.

21. Wang, D.; Liu, Y.; Yang, Y.; Xiao, D. Theoretical and experimental study on surface roughness of 316L stainless steel metal parts obtained through selective laser melting. Rapid Prototyp. J. 2016, 22, 706-716. [CrossRef]

22. Bourell, D.; Kruth, J.P.; Leu, M.; Levy, G.; Rosen, D.; Beese, A.M.; Clare, A. Materials for additive manufacturing. CIRP Ann. Manuf. Technol. 2017, 66, 659-681. [CrossRef]

23. Nespoli, A.; Biffi, C.A.; Previtali, B.; Villa, E.; Tuissi, A. Laser and surface processes of NiTi shape memory elements for micro-actuation. Metall. Mater. Trans. A. 2014, 45, 2242-2249. [CrossRef]

24. Mingear, J.; Zhang, B.; Hartl, D.; Elwany, A. Effect of process parameters and electropolishing on the surface roughness of interior channels in additively manufactured nickel-titanium shape memory alloy actuators. Addit. Manuf. 2019, 27, 565-575. [CrossRef]

25. Wang, X.; Xia, W.; Wu, X.; Wei, Y.; Huang, C. Microstructure and mechanical properties of an austenite NiTi shape memory alloy treated with laser induced shock. Mater. Sci. Eng. A 2013, 578, 1-5. [CrossRef]

26. Wang, H.; Pöhl, F.; Yan, K.; Decker, P.; Gurevich, E.L.; Ostendorf, A. Effects of femtosecond laser shock peening in distilled water on the surface characterizations of NiTi shape memory alloy. Appl. Surf. Sci. 2019, 471, 869-877. [CrossRef]

27. Hou, X.; Mankoci, S.; Walters, N.; Gao, H.; Zhang, R.; Li, S.; Qin, H.; Ren, Z.; Doll, G.L.; Cong, H.; et al. Hierarchical structures on nickel-titanium fabricated by ultrasonic nanocrystal surface modification. Mater. Sci. Eng. 2018, 93, 12-20. [CrossRef] [PubMed]

28. Ye, C.; Zhou, X.; Telang, A.; Gao, H.; Ren, Z.; Qin, H.; Suslov, S.; Gill, A.S.; Mannava, S.; Qian, D.; et al. Surface amorphization of NiTi alloy induced by Ultrasonic Nanocrystal Surface Modification for improved mechanical properties. J. Mech. Behav. Biomed. Mater. 2016, 53, 455-462. [CrossRef] [PubMed]

29. Ma, C.; Andani, M.T.; Qin, H.; Moghaddam, N.S.; Ibrahim, H.; Jahadakbar, A.; Amerinatanzi, A.; Ren, Z.; Zhang, H.; Doll, G.L.; et al. Improving surface finish and wear resistance of additive manufactured nickel-titanium by ultrasonic nano-crystal surface modification. J. Mater. Process. Technol. 2017, 249, 433-440. [CrossRef]

30. Mitwally, M.E.; Farag, M. Effect of cold work and annealing on the structure and characteristics of NiTi alloy. Mater. Sci. Eng. A 2009, 519, 155-166. [CrossRef]

(C) 2019 by the authors. Licensee MDPI, Basel, Switzerland. This article is an open access article distributed under the terms and conditions of the Creative Commons Attribution (CC BY) license (http://creativecommons.org/licenses/by/4.0/). 